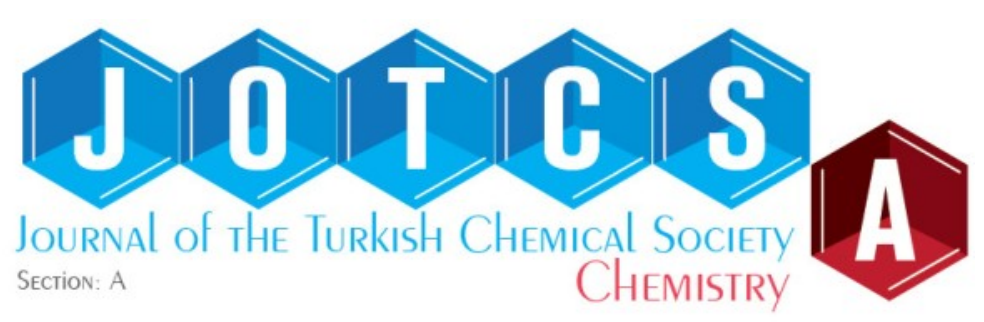

\section{Modeling and Regeneration Studies for the Removal of Crystal Violet Using Balanites aegyptiaca Seed Shell Activated Carbon}

\author{
Umar Yunusa $^{1 *} D$, Bishir Usman ${ }^{1} D$ and Muhammad Bashir Ibrahim ${ }^{1}$ \\ ${ }^{1}$ Department of Pure and Industrial Chemistry, Bayero University, P.M.B.3011, BUK, Kano-Nigeria.
}

Keywords: Adsorption, Balanites aegyptiaca, crystal violet, modeling, regeneration.

Submitted: March 5, 2020. Accepted: December 21, 2020.

Cite this: Yunusa U, Usman B, Ibrahim M. Modeling and Regeneration Studies for the Removal of Crystal Violet Using Balanites aegyptiaca Seed Shell Activated Carbon. JOTCSA. 2021;8(1):195-208.

DOI: https://doi.org/10.18596/jotcsa.698959.

*Corresponding author. E-mail: umaryunusa93@gmail.com.

\section{INTRODUCTION}

Water pollution is among the most terrible environmental problems globally and therefore needs pressing attention (1). Numerous toxic substances such as synthetic dyes, heavy metals, pesticides, and aromatic compounds are encountered in the wastewater emanating from various industries (2). The major source of industrial wastewater is the textile industry because of its high water utilization for dyeing and finishing processes (3). The presence of the aforementioned pollutants adversely affects water quality and is among the major cause of diseases and gives harm to human well-being $(4,5)$. Among the different categories of pollutants, dyes are exclusively noticeable to the bare eye even at minute concentrations. The adverse effects of dyes can be terrible depending on their class, concentration, and period of exposure (6). There are different classes of dyes (basic, direct, acidic, reactive, dispersive, sculpture, and metallic dyes) that fall into the neutral, anionic, and cationic categories. Basic dyes and diazo direct dyes have been observed to have the highest level of toxicity (7).

Crystal violet (CV), also referred to as Basic Violet 3, is a basic dye that belongs to a category of intensely colored compounds called triarylmethane dyes. CV is one of the most widely employed coloring agents in numerous application context (8). It is extensively 
utilized in painting, textile dyeing, histological staining, printing, dermatology, and veterinary fields $(9,10)$. However, the presence of $C V$ in aqueous medium has deleterious effect on human health as it is proven as mutagenic, carcinogenic, and also causes skin irritation upon contact with the body $(11,12)$. Therefore, adequate treatment is needed to remove it from wastewater before disposing in to the environment.

In the last decades, activated carbon has been widely employed in the reclamation of pollutant-bearing wastewater due to its high removal efficiency. However, the high cost of the commercial activated carbon makes it imperative to search for cheaper alternatives, mainly from agricultural biomass (13). Balanites aegyptiaca is an evergreen, multi-branched and spiny tree grown in the dry and savannah areas of Africa and southern Asia (14). It is widely used for different purpose in Nigeria and this lead to generation of colossal amount of waste as Balanites aegyptiaca seed shell (BESS). Relevant studies on the use of this agricultural waste are relatively few. Specifically, no report was documented on the removal of $\mathrm{CV}$ by this form of material.

The present work is aimed at probing the feasibility of using activated carbon derived from BESS as alternative adsorbent for CV removal from aqueous medium. In particular, the prepared adsorbent was characterized using scanning electron microscopy (SEM) interfaced with energy dispersive spectroscopy (EDS) and Brunauer-Emmett-Teller (BET) surface area analysis. The kinetic and isotherm data for $\mathrm{CV}$ adsorption on ACBS were analyzed using different mathematical models. Also, the thermodynamic quantities were computed in order to ascertain the feasibility of the removal process. Finally, regeneration study was conducted to establish the recovery and recycling of the ACBS.

\section{MATERIALS AND METHODS}

\section{Preparation and characterization of activated carbon}

The activated carbon preparation was mainly guided by the procedure described by (15), but substituting $\mathrm{KOH}$ for $\mathrm{NaOH}$ chemical activator. Balanites aegyptiaca seed shells were sourced locally, thoroughly washed, oven-dried and reduced to smaller particle size $(1 \mathrm{~mm})$. The sample was then subjected to first pyrolysis at $700{ }^{\circ} \mathrm{C}$ in a furnace for $90 \mathrm{~min}$. A certain quantity of the resulting char was impregnated with $\mathrm{NaOH}$ with the impregnation ratio set at 2:1 ( $\mathrm{NaOH}$ pellets: char). This was followed by second pyrolysis at $750{ }^{\circ} \mathrm{C}$ and activated for $90 \mathrm{~min}$. The activated product was subsequently cooled, leached with $250 \mathrm{~mL}$ dilute $\mathrm{HCl}$ and then finally washed with distilled water until the washing solution $\mathrm{pH}$ attained a neutral value.

The surface structure of the activated carbon and elemental composition were analyzed using scanning electron microscope interfaced with energy dispersive spectrometer (PRO: X: Phenonm World 800-07334). The scanning of the sample was done at an accelerating voltage of $15.00 \mathrm{kV}$ and 500 times magnification. The BET surface area, micropore volume, and average pore diameter of the ACBS was estimated by $\mathrm{N}_{2}$ adsorption method at $77 \mathrm{~K}$, using Quanta Chrome NOVA 2200e, surface area, and pore size analyzer.

\section{Preparation of adsorbate solution}

CV procured from E. Merck (Mumbai, India) was used as an adsorbate and was not subjected to any further purification prior to use. Stock solution (1000 mg/L) was prepared by dissolving $1.0 \mathrm{~g}$ of the dye into $1 \mathrm{~L}$ distilled water in a standard graduated flask. Working $\mathrm{CV}$ solution of different concentrations were prepared by employing successive dilution method. The aqueous phase initial $\mathrm{pH}$ was changed accordingly using $0.1 \mathrm{M} \mathrm{NaOH}$ or $0.1 \mathrm{M} \mathrm{HCl}$ solution and was monitored using pH meter (3510 model, Jenway).

\section{Analysis of crystal violet}

The final concentration of $\mathrm{CV}$ in the supernatant obtained after adsorption was analyzed using a UV/Vis spectrophotometer (Labda 35; Perkin Elmer) at maximum absorbance wavelength $\left(\lambda_{\max }\right)$ of $591 \mathrm{~nm}$. Standard solutions $(2-10 \mathrm{mg} / \mathrm{L})$ of the adsorbate were prepared and absorbance values were recorded to obtain the calibration curve. The residual dye concentration was determined with reference to the linear calibration curve by interpolation.

\section{Experimental protocol}

Batch adsorption experiments were conducted in an Innova 4000 shaker (New Brunswick Scientific). The extent of CV dye removal was studied to assess the influence of varied operational parameters such as temperature (303-313 K), contact time (5-120 min), and initial adsorbate concentration (100-500 mg/L). The influence of each process parameter was investigated by altering that parameter while keeping alternate factors constant. Adsorbate solutions (50 $\mathrm{mL}$ ) of fixed concentration were contacted with a fixed dose $(0.15 \mathrm{~g})$ of ACBS in $250 \mathrm{ml}$ conical flasks. The $\mathrm{pH}$ of the aqueous solutions were adjusted to a predetermined optimum $\mathrm{pH}$ of 8.0 . The contents were then agitated at $150 \mathrm{rpm}$ under controlled temperature $\left(30 \pm 1{ }^{\circ} \mathrm{C}\right)$ in an incubator shaker. After pre-decided times, each sample was collected and then centrifuged at $5000 \mathrm{rpm}$ for $10 \mathrm{~min}$. Finally, the clear supernatant was decanted and analyzed for final dye concentration. To attest the correctness and reproducibility of the results, all the experiments were triplicated under same experimental conditions. The 
extent of dye adsorption at equilibrium, $\mathrm{q}_{\mathrm{e}}(\mathrm{mg} / \mathrm{g})$, was computed using Eq. 1:

$$
q_{e}=\left(\frac{C_{0}-C_{e}}{m}\right) \times V
$$

where $C_{o}$ and $C_{e}(m g / L)$ stand for the initial and equilibrium liquid phase concentrations, respectively. $V$ is the volume of the dye solution (L), and $m$ is the dry mass of the adsorbent $(\mathrm{g})$.

\section{Kinetic studies}

The protocol was essentially the same to those highlighted in the batch experiment. The difference is that the samples were collected after pre-decided times of $5,10,20,30,40,60,90$, and $120 \mathrm{~min}$. The supernatant obtained after adsorption was analyzed for concentration of the unadsorbed dye. The extent of dye uptake at time $\mathrm{t}, \mathrm{q}_{\mathrm{t}}(\mathrm{mg} / \mathrm{g})$ was obtained using Eq. 2:

$$
q_{t}=\left(\frac{C_{0}-C_{t}}{m}\right) \times V
$$

where $C_{o}$ and $C_{t}(\mathrm{mg} / \mathrm{L})$ are the aqueous-phase $\mathrm{CV}$ concentrations at initial and any time $t$, respectively. $V$ is the dye solution volume (L), and $m$ is the dry mass of the adsorbent $(\mathrm{g})$. The kinetics of the CV removal was examined using the pseudo-first-order (16), and pseudo-second-order models (17). The linear equations representing the models are expressed by Eqs. 3-4, respectively:

$$
\begin{aligned}
\ln \left(q_{e}-q_{t}\right)=\ln q_{e}-k_{1} t \\
\frac{t}{q_{t}}=\frac{1}{k_{2} q_{e}^{2}}+\frac{t}{q_{e}}
\end{aligned}
$$

where $k_{1}(1 / \mathrm{min})$ and $k_{2}(g / m g ~ m i n)$ represent the pseudo-first and pseudo-second-order rate constants, respectively. $k_{1}$ value can be computed from the gradient of the graph of $\ln \left(q_{e}-q_{t}\right)$ against $t$. Similarly, the $k_{2}$ and $q_{e}$ values can be evaluated from the intercept and gradient of linear graph of $t / q_{t}$ against $t$, respectively. The fitting and applicability of each kinetic model was verified using the coefficient of interrelationship $\left(\mathrm{R}^{2}\right)$ and sum of error squares (SSE, $\%$ ) which was computed using Eq. 5 (18):

$$
\operatorname{SSE}(\%)=\sqrt{\frac{\sum\left(q_{e, \exp }-q_{e, \text { theo }}\right)^{2}}{N}}
$$

where $\mathrm{N}$ is the data points number, $\mathrm{q}_{\mathrm{e}, \text { cal }}$ and $\mathrm{q}_{\mathrm{e}, \mathrm{exp}}(\mathrm{mg} /$ g) represent the calculated and experimental adsorption capacity, respectively.

\section{Diffusion studies}

The diffusion mechanisms of $\mathrm{CV}$ adsorption onto the ACBS were explored using intraparticle diffusion (19) and Boyd (20) models expressed mathematically by Eqs. 6 and 7, respectively. The fitting of the kinetic data into the models gives insight into the rate limiting step of the adsorption process.

$$
\begin{aligned}
& q_{t}=k_{i d} t^{1 / 2}+C \\
& B_{t}=-0.4977-\ln \left(1-\frac{q_{t}}{q_{e}}\right)
\end{aligned}
$$

where, $k_{\text {id }}$ represent the intra-particle diffusion rate constant $\left(\mathrm{mg} / \mathrm{min}^{1 / 2} \mathrm{~g}\right)$ and its value can be gotten from the gradient of the graph of $q_{t}$ against $t^{1 / 2} ; C$ is the intercept which reflects the boundary layer thickness and $B_{t}$ is the function of the fraction of adsorbate removed at time $t$.

\section{Isotherms studies}

Isotherm study was conducted with higher initial dye concentrations of $100,200,300,400$, and $500 \mathrm{mg} / \mathrm{L}$. The isotherm data for CV adsorption on ACBS were modelled by fitting them to Freundlich, Langmuir, Elovich, Dubinin-Radushkevic, Jovanovic, and Temkin isotherm models. The linear equations representing the models are given by Eqs. 8-13 (21):

$$
\begin{array}{r}
\log q_{e}=\log K_{F}+\frac{1}{n} \log C_{e}{ }_{\text {(Freundlich) }} \\
\frac{C_{e}}{q_{e}}=\frac{C_{e}}{q_{m}}+\frac{1}{K_{L} q_{m}} \quad \text { (Langmuir) } \\
\ln \frac{q_{e}}{C_{e}}=\ln K_{e q m}-\frac{q_{e}}{q_{m}} \text { (Elovich) }
\end{array}
$$

$$
\begin{array}{r}
\ln q_{e}=\ln q_{m}-\beta \varepsilon^{2} \text { (Dubinin-Radushkevich) } \\
\ln q_{e}=\ln q_{m}-K_{J} C_{e} \text { (Jovanovic) } \\
q_{e}=\frac{R T}{b} \ln C_{e}+\frac{R T}{b} \ln K_{T}
\end{array}
$$


where $\mathrm{K}_{\mathrm{F}}, \mathrm{K}_{\mathrm{L}}, \mathrm{K}_{\mathrm{e}}, \mathrm{K}_{\mathrm{J}}$. and $\mathrm{K}_{\mathrm{T}}$ are Freundlich, Langmuir, Elovich, Jovanovic and Temkin isotherm constants, respectively; $\mathrm{q}_{\mathrm{e}}$ and $\mathrm{q}_{\mathrm{m}}$ represent the equilibrium and maximum monolayer adsorption capacity $(\mathrm{mg} / \mathrm{g})$ of the ACBS, respectively; $C_{e}(\mathrm{mg} / \mathrm{L})$ represent the equilibrium CV concentration, $\varepsilon$ is the polanyi potential, $\beta\left(\mathrm{mol}^{2} / \mathrm{J}^{2}\right)$ and $\mathrm{b}(\mathrm{J} / \mathrm{mol})$ are constants associated with the adsorption energy. The suitability of the isotherm equation is assessed by comparing the coefficients of interrelationship, $\mathrm{R}^{2}$.

\section{Thermodynamic studies}

The thermodynamic experiments were similar to the kinetic study except that the experiment were performed at varying temperatures of $303,313,323$ and $333 \mathrm{~K}$. The values of the thermodynamic quantities such as entropy change $\left(\Delta \mathrm{S}^{\circ}\right)$, Gibbs free energy change $\left(\Delta \mathrm{G}^{\circ}\right)$, and enthalpy change $\left(\Delta \mathrm{H}^{\circ}\right)$ were computed using Eqs. 14-16 (22):

$$
\begin{gathered}
K_{d}=\frac{C_{a d s}}{C_{e}} \\
\Delta G^{\circ}=-R T \ln K_{d} \\
\Delta G^{o}=\Delta H^{o}-T \Delta S^{o}
\end{gathered}
$$

where, $C_{a d s}$ and $C_{e}(\mathrm{mg} / \mathrm{L})$ are equilibrium CV concentration of on the ACBS and in the liquid phase, respectively; $K_{d}$ represents the equilibrium constant of adsorption, $\mathrm{R}$ represent the gas constant $[8.314 \mathrm{~J} /(\mathrm{K}$ $\mathrm{mol})$ ] and $\mathrm{T}$ represent the temperature $(\mathrm{K})$. The values of $\Delta \mathrm{S}^{\circ}$ and $\Delta \mathrm{H}^{\circ}$ were obtained from the gradient and intercept of the plot of $\Delta \mathrm{G}^{\circ}$ against $\mathrm{T}$, respectively.

\section{Regeneration studies}

Regeneration experiments were performed to investigate the feasibility of recycling the spent adsorbent and recovery of the dye from aqueous phase. The ACBS regeneration was explored by batch desorption using neutral, basic, and acidic desorbing solutions: distilled water, $0.1 \mathrm{M} \mathrm{NaOH}, 0.1 \mathrm{M} \mathrm{H}_{2} \mathrm{SO}_{4}$, $0.1 \mathrm{M} \mathrm{HCl}, 0.1 \mathrm{M} \mathrm{HNO}_{3}$ and $0.1 \mathrm{M} \mathrm{CH}_{3} \mathrm{COOH}$. CVenriched adsorbent was prepared by shaking $0.15 \mathrm{~g}$ of adsorbent with $50 \mathrm{~mL}$ of $50 \mathrm{mg} / \mathrm{L}$ CV solution at 150 rpm for 120 in a shaker at $303 \mathrm{~K}$. In desorption experiments, the CV-enriched adsorbent was added to $50 \mathrm{~mL}$ of $0.1 \mathrm{M}$ of the aforementioned desorbing solutions. The contents were shaken at $150 \mathrm{rpm}$ for $120 \mathrm{~min}$ and the supernatant was analyzed for the desorbed dye concentration. The desorbing solution concentration effect was investigated using the eluent offering higher dye recovery. Similar protocol was applied but with different acetic acid concentration of $0.05,0.1,0.2,0.3,0.4,0.5$, and $1.0 \mathrm{M}$. The influence of contact time on desorption was also probed using $0.5 \mathrm{M} \mathrm{CH}_{3} \mathrm{COOH}$ at varying time of $5,10,20,30,60$, 90 , and $120 \mathrm{~min}$. The reusability of the ACBS was evaluated using 5 successive cycles of adsorptionregeneration and the amount adsorbed/desorbed at various cycles was recorded. The desorption efficiency was computed using the following equation:

$$
\text { Desorption efficiency }(\%)=\frac{C_{d e s}}{C_{a d s}} \times 100
$$

Where, $C_{\text {des }}$ and $C_{\text {ads }}$ stand for the concentration of CV desorbed and adsorbed in $\mathrm{mg} / \mathrm{L}$, respectively.

\section{RESULTS AND DISCUSSION}

\section{SEM-EDS and BET analyses}

The conversion of the precursor into activated carbon was normally associated with changes in morphology that were verified by conduction of pre- and postactivation SEM analysis of the sample. As observed in Figure $1(a)$, the surface of the BESS is rough and nonporous with some crevices. However, Figure 1(b) revealed variation in the surface texture of the precursor after the activation process with prominent pores existing on the ACBS surface. The development of pores was attributed to the breakdown of some lignocellulose at high activation temperature and subsequent loss of thermally labile compounds (23). The loaded adsorbent was also subjected to analysis and appreciable changes were observed as illustrated in Figure 1 (c). It can be seen that the number of pores diminished which might be ascribed to the occupation of the adsorbent surface by dye molecules. The EDS spectrum of the activated carbon was obtained to ascertain the elemental content (weight \% of elements). Figure 2 illustrates that the EDS spectrum consist of peaks of C, O, N, P, S, and Cl. The results showed that the atomic percentages of the adsorbent before and after adsorption process as acquired by EDS quantification were C (82.98, $86.94 \%)$, O $(13.16,6.89 \%), N(2.78,5.93 \%)$ P $(0.95$, $0.11 \%), \mathrm{S}(0.13,0.10 \%)$ and $\mathrm{Cl}(0.00,0.04 \%)$, respectively. The changes in the atomic percentages are indication of the uptake of the $\mathrm{CV}$ by the adsorbent. The BET surface area, micropore volume, and average pore diameter were computed to be $700.29 \mathrm{~m}^{2} \mathrm{~g}^{-1}, 0.283 \mathrm{~cm}^{3} \mathrm{~g}^{-1}$, and $19.41 \mathrm{~nm}$, respectively. The higher surface area of ACBS is reflective of it good adsorption capability. 


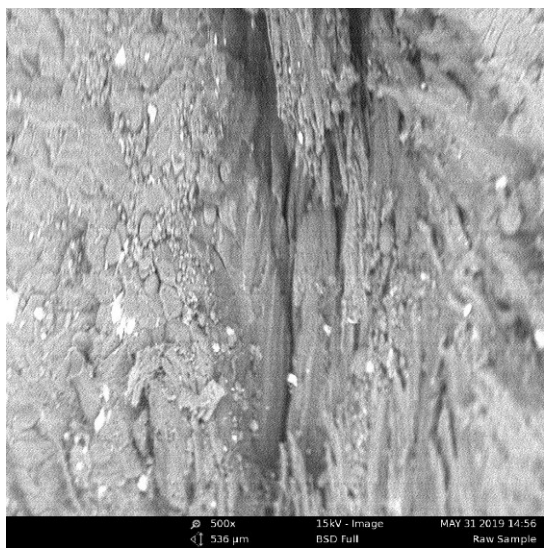

a

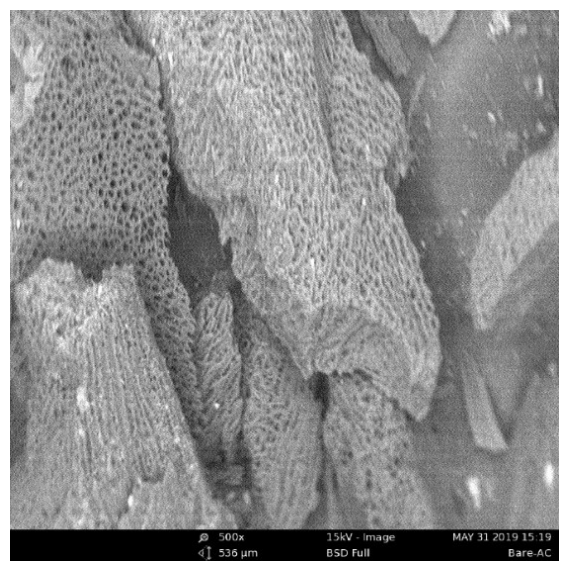

b

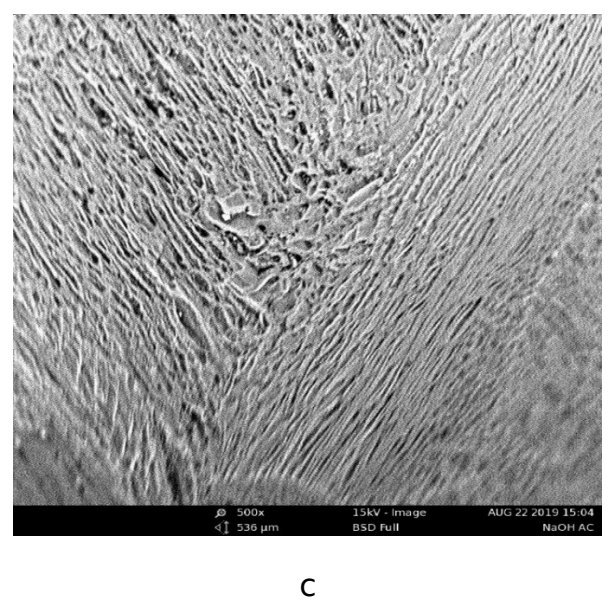

Figure 1: SEM micrograph of (a) BESS (b) ACBS (c) ACBS-CV.

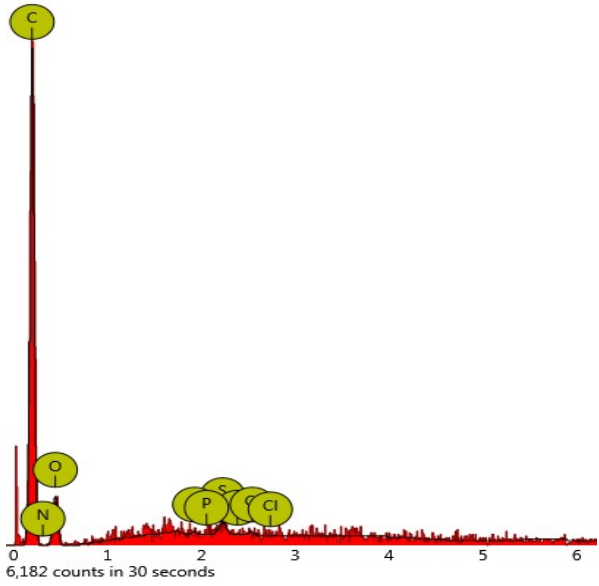

a

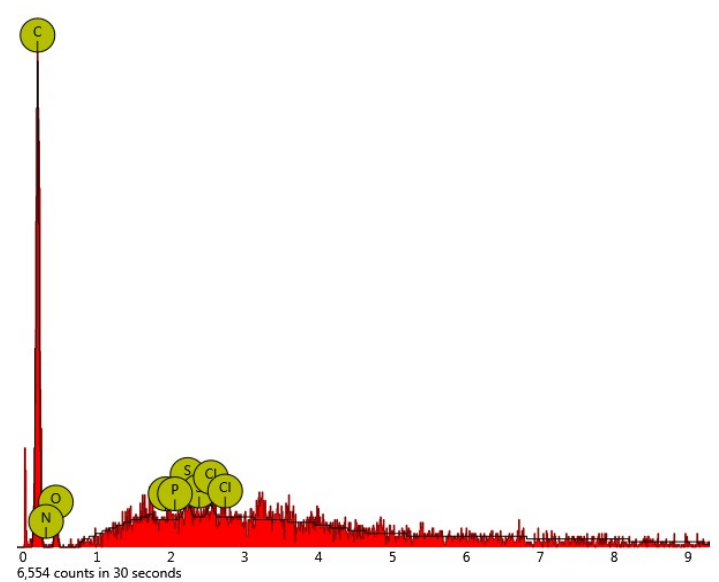

b

Figure 2: EDS spectra of ACBS (a) before and (b) after CV adsorption. 


\section{Kinetic studies}

The graphs for pseudo-first-order and pseudo-secondorder models are depicted in Figures 3 and 4, and the relevant parameters obtained from the plots are presented in Table 1. It is clear that the kinetic data align with the pseudo-second-order model $\left(\mathrm{R}^{2}=\right.$ 0.9999 for all initial CV concentrations). Also, the theoretical $\mathrm{q}_{\mathrm{e}, \mathrm{cal}}$ value computed from the pseudosecond-order model was in conformity to the experimental value, which indicates the suitability of the model for the observed kinetics. Moreover, the pseudo-second-order model exhibited a relatively

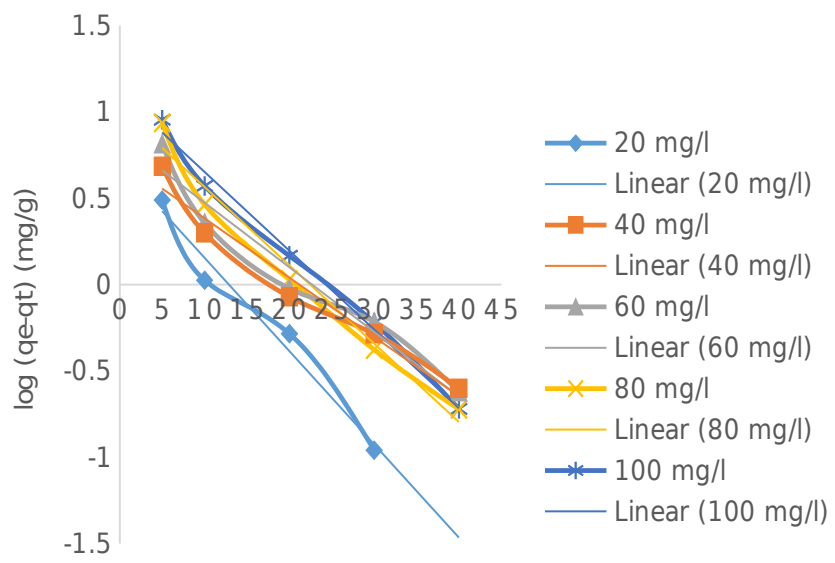

$t(\min )$ lower value of the calculated sum of error squares (SSE, \%) than the pseudo-first-order model as shown in Table 1. The pseudo-second-order rate constant $k_{2}$, was observed to decline with increase in adsorbate concentration. This signifies slower adsorption rate at higher CV concentration. The results give a hint that chemisorption was the most favored mechanism in the uptake of the adsorbate by the adsorbent. Similar trend in kinetics was highlighted for the sorption of methylene blue onto Terminalia catappa and Jatropha curcas seed coats activated carbon (24).

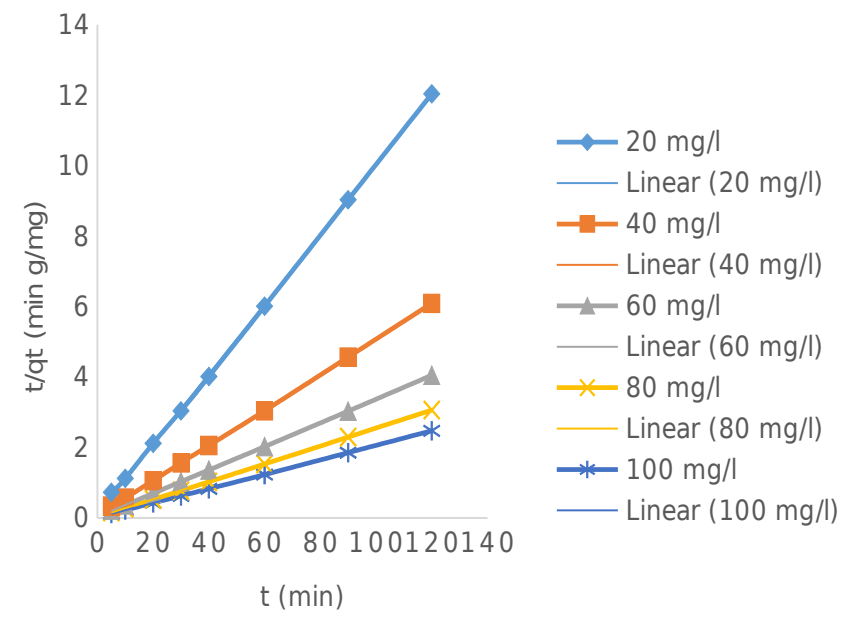

Figure 3: Pseudo-first-order fit for the adsorption of CV Figure 4: Pseudo-second-order fit for the adsorption of onto ACBS $(\mathrm{N}=5)$. CV onto ACBS $(\mathrm{N}=8)$.

Table 1: Kinetic parameters for $C V$ adsorption at various initial concentrations.

\begin{tabular}{|c|c|c|c|c|c|c|}
\hline \multirow[t]{2}{*}{ Kinetic model } & \multirow[t]{2}{*}{ Parameters } & \multicolumn{5}{|c|}{ Initial CV concentration (mg/L) } \\
\hline & & 20 & 40 & 60 & 80 & 100 \\
\hline \multirow[t]{5}{*}{ Pseudo-first-order } & $\mathrm{k}_{1}\left(\min ^{-1}\right)$ & 0.124 & 0.078 & 0.086 & 0.104 & 0.105 \\
\hline & $q_{e \exp }(m g / g)$ & 9.97 & 19.71 & 29.64 & 39.21 & 48.55 \\
\hline & $\mathrm{q}_{\mathrm{e} \text { cal }}(\mathrm{mg} / \mathrm{g})$ & 4.96 & 5.34 & 7.06 & 10.45 & 12.84 \\
\hline & $\mathrm{R}^{2}$ & 0.9708 & 0.9615 & 0.9529 & 0.9743 & 0.9915 \\
\hline & SSE (\%) & 2.51 & 6.43 & 10.09 & 12.86 & 15.97 \\
\hline \multirow[t]{5}{*}{ Pseudo-second order } & $\mathrm{k}_{2}(\mathrm{~g} / \mathrm{mg} \min )$ & 0.075 & 0.040 & 0.031 & 0.021 & 0.020 \\
\hline & $q_{e \exp }(m g / g)$ & 9.97 & 19.71 & 29.64 & 39.21 & 48.55 \\
\hline & $\mathrm{q}_{\mathrm{e} \mathrm{cal}}(\mathrm{mg} / \mathrm{g})$ & 10.12 & 19.96 & 29.94 & 39.53 & 49.01 \\
\hline & & 0.9998 & 0.9999 & 0.9999 & 0.9999 & 0.9999 \\
\hline & SSE (\%) & 0.08 & 0.11 & 0.13 & 0.14 & 0.21 \\
\hline
\end{tabular}

\section{Diffusion studies}

The adsorption process customarily involved four stages: (a) bulk movement of adsorbate from solution to the liquid film enclosing the adsorbent; (b) mass movement of adsorbate across the liquid film to the outer surface of the adsorbent, which is referred to as boundary layer diffusion (or film diffusion); (c) adsorbate transport from outer surface into the pores of the adsorbent, which is referred to as pore diffusion (intraparticle diffusion or internal diffusion); (d) adsorption of adsorbate onto active sites in interior and exterior surfaces of adsorbent (25). To establish the rate-controlling step of the CV removal process, the intraparticle diffusion and Boyd models were engaged and the results were illustrated in Figures 5 and 6. As depicted in Figure 5, the intraparticle diffusion plot exhibited two different linear portions, implying two different steps in the CV uptake by the 
adsorbent (26). The first portion is ascribed to the diffusion of the dye molecules into the pores of the ACBS, whereas the last portion represents the equilibrium phase where pore diffusion starts to dropoff due to low residual dye concentration in the solution (27). The boundary layer effect was observed to be significant as reflected by the large values of the intercept (Table 2). This indicates the involvement of film diffusion in the rate controlling step (28). The plot reveals that the boundary layer thickness is proportional to the dye concentration in solution. This implies that the more concentrated the dye solution, the more the time that will be required for the dye molecules to move from solution into the pores of the adsorbent.

The experimental kinetic data were further tested with the Boyd model in order to establish the ratecontrolling step and the plot is exposed in Figure 6. It is observed that the plots in Figure 6 exhibited nonzero intercepts, confirming the participation of film diffusion in the adsorption process. However, the plots are non-linear, implying that film diffusion shows a relatively low control for dye adsorption onto ACBS (29).

\section{Isotherm studies}

The study of adsorption isotherms gives insight about the distribution of solute molecules between the aqueous and solid phases at equilibrium. Figures 7(af) typically illustrate the isotherms of the dye adsorption at $303 \mathrm{~K}$, and the values of the characteristic empirical constants were given in Table 3. Examination of the interrelationship coefficients hint that the Freundlich model yielded the best matching of the isotherm data for CV adsorption onto ACBS. The order of the best matching is found to be: Freundlich > Elovich > Langmuir > Temkin > D-R > Jovanovic. The applicability of the Freundlich isotherm intimates the multilayer coverage of the adsorbate on the heterogeneous surface of the adsorbent (30). These findings were in accord with previous reports where the Freundlich isotherm gives better conformation for the sorption of $\mathrm{CV}$ by various adsorbents $(31,32)$. Furthermore, the $1 / n$ value $(0.56)$ demonstrates higher heterogeneity and that physical adsorption administrates the uptake of the dye by the porous carbon (33). The Langmuir model also yield a relatively good match $\left(R^{2}=0.9869\right)$, implying compatibility of the data to the model. This attest the partial involvement of monolayer type mechanism in the adsorption process (34). The value of $R_{L}$ obtained (0.11) is illustrative of the favorability of the CV adsorption onto the activated carbon (35). The equilibrium data is also compatible with the Elovich model $\left(R^{2}=0.9875\right)$, and this implies multilayer adsorption on the carbon surface (36). The data was also fit in the Temkin isotherm to determine the energy associated with the CV-ACBS interaction. The obtained value of the Temkin constant, b (150.06 $\mathrm{J} / \mathrm{mol}$ ) is a signifier of the physical character of the adsorption (37) and this aligns with the multilayer principle. The energy of adsorption (E) from D-R model $(1.29 \mathrm{~kJ} / \mathrm{mol})$ is less than $8 \mathrm{~kJ} / \mathrm{mol}$, testifying that the adsorption process is governed by weak physical forces (38). The poor matching of the data to the Jovanovic model recommend the non-suitability of the model in interpreting the results.

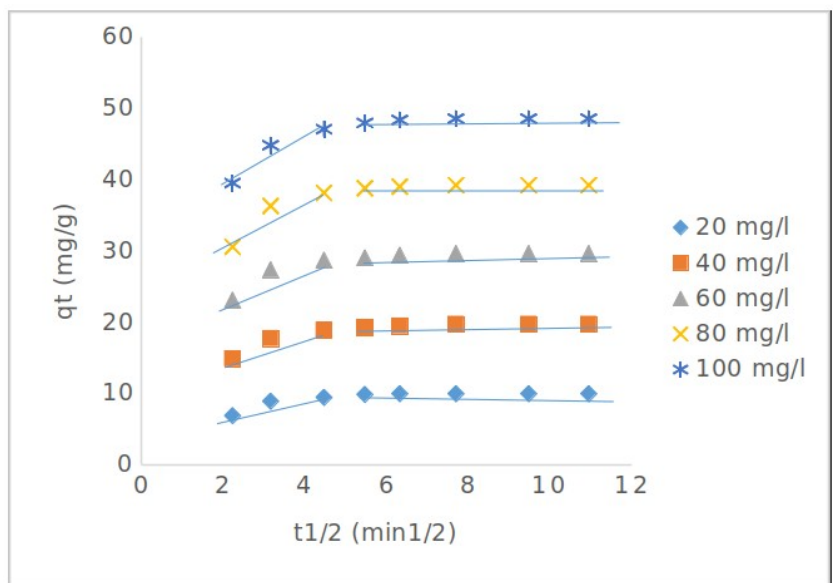

Figure 5: Intraparticle diffusion plot for CV adsorption onto ACBS.

Table 2: Intraparticle diffusion model parameters.

\begin{tabular}{lll}
\hline $\mathrm{C}_{0}(\mathrm{mg} / \mathrm{L})$ & $\begin{array}{l}\mathrm{K}_{\text {id }}(\mathrm{g} / \mathrm{mg} \\
\min )\end{array}$ & $\mathrm{C}$ \\
\hline 20 & 0.26 & 7.76 \\
40 & 0.43 & 15.99 \\
60 & 0.55 & 24.89 \\
80 & 0.71 & 33.13 \\
100 & 0.79 & 41.77 \\
\hline
\end{tabular}

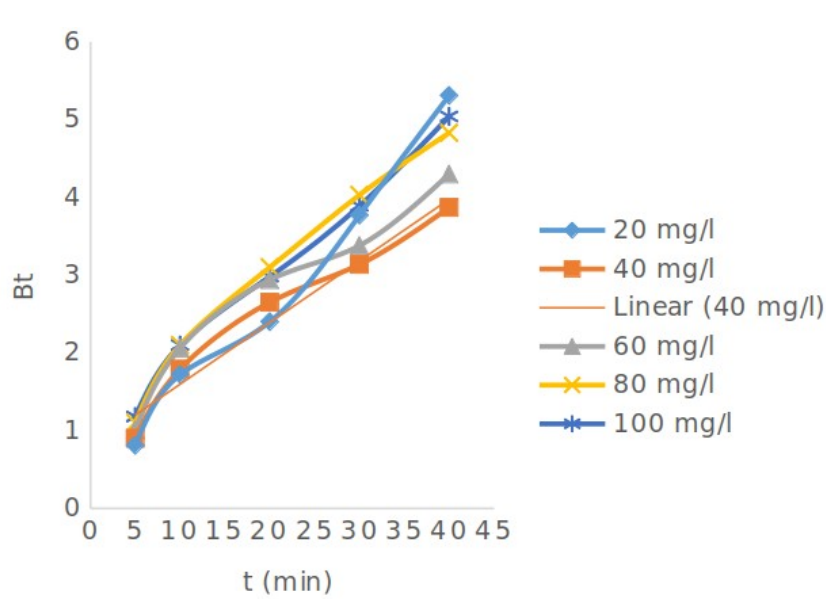

Figure 6: Boyd plot for $C V$ adsorption onto $A C B S$. 


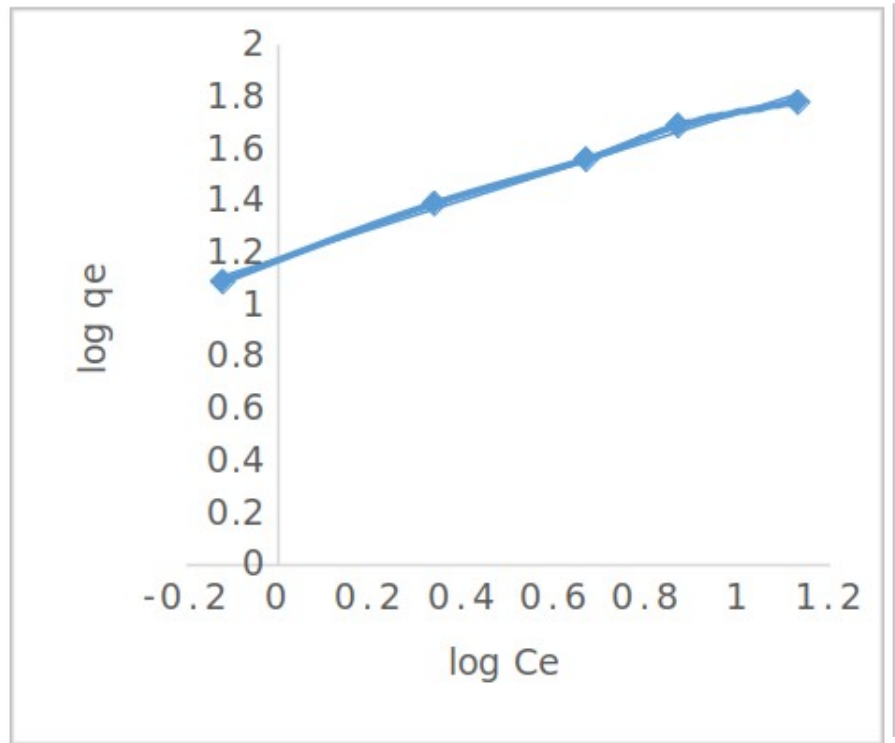

(a)

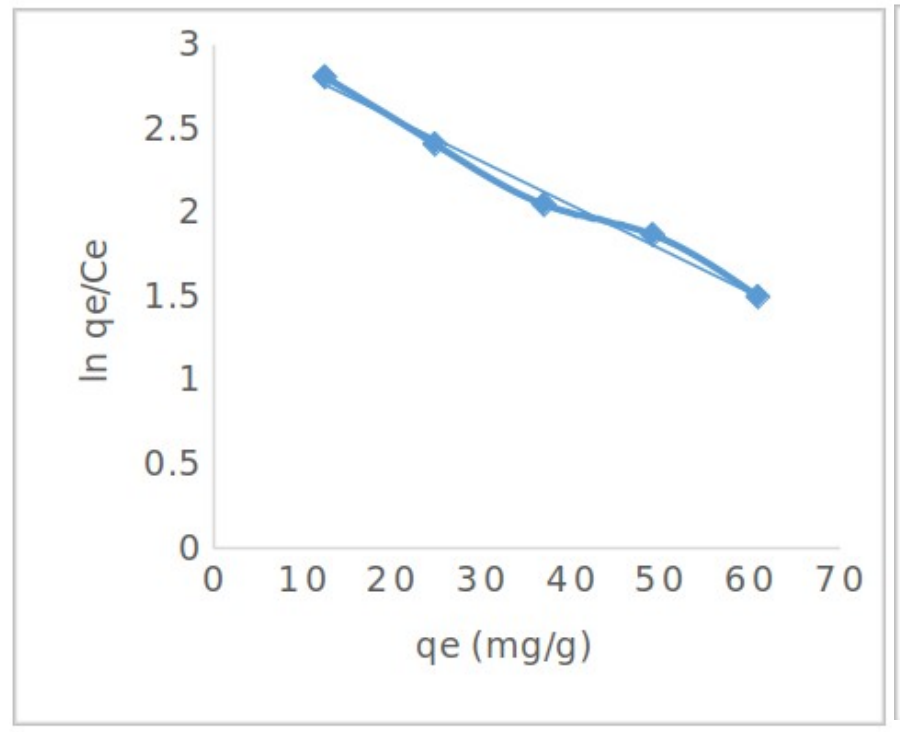

(c)

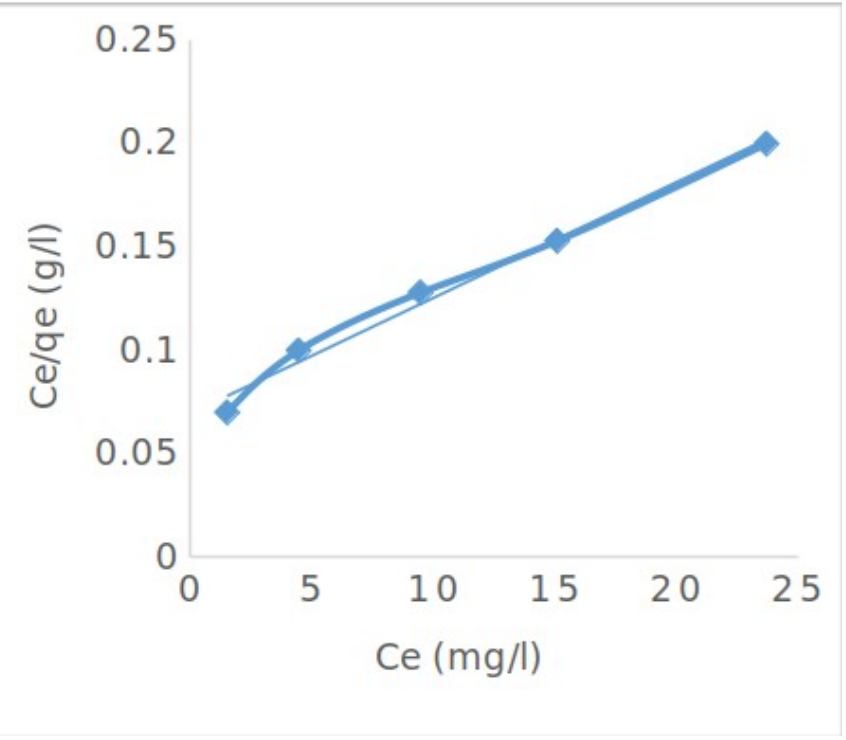

(b)

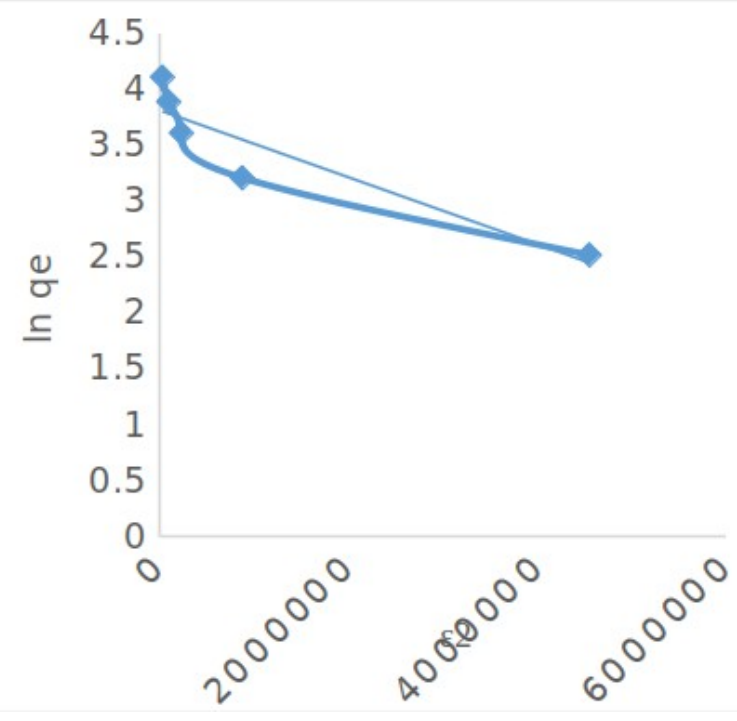

(d) 


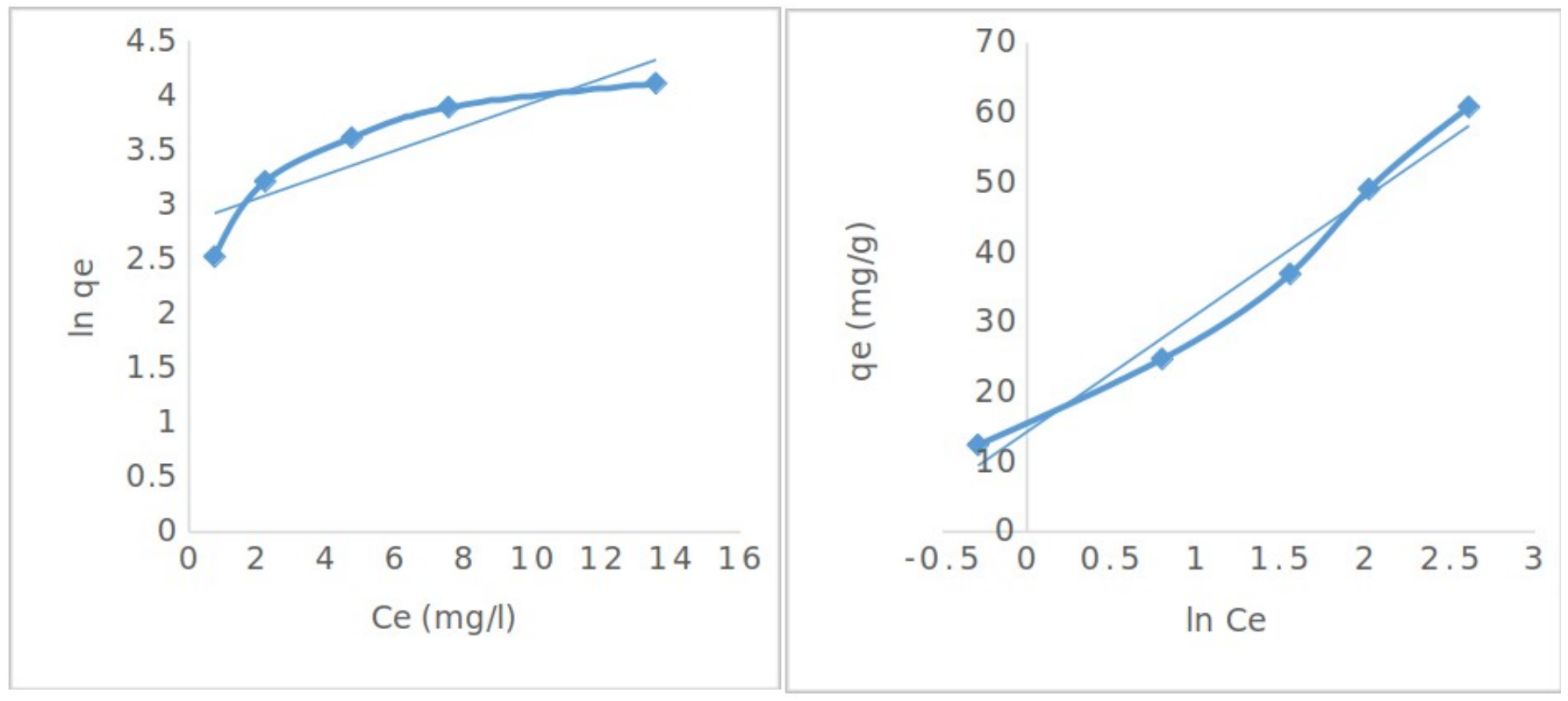

(e)

Figure 7: Isotherm fits for (a) Freundlich, (b) Langmuir, (c) Elovich, (d) Dubinin-Radushkevich, (e) Jovanovic, and (f) Temkin isotherm models.

Table 3: Isotherm parameters for $\mathrm{CV}$ adsorption onto ACBS.

\begin{tabular}{lll}
\hline Isotherm models & Parameters & Values \\
\hline Langmuir & $\mathrm{q}_{\mathrm{m}}(\mathrm{mg} / \mathrm{g})$ & 178.57 \\
& $\mathrm{~K}_{\mathrm{L}}\left(\mathrm{dm}^{3} / \mathrm{mg}\right)$ & 0.08 \\
& $\mathrm{R}_{\mathrm{L}}$ & 0.11 \\
& $\mathrm{R}^{2}$ & 0.9869 \\
Freundlich & $\mathrm{K}_{\mathrm{F}}\left(\mathrm{dm}^{3} / \mathrm{mg}\right)$ & 15.07 \\
& $1 / \mathrm{n}$ & 0.56 \\
Temkin & $\mathrm{R}^{2}$ & 0.9916 \\
& $\mathrm{~K}_{\mathrm{T}}\left(\mathrm{dm}^{3} / \mathrm{mg}\right)$ & 0.85 \\
D-R & $\mathrm{b}\left(\mathrm{J} / \mathrm{mol}^{\prime}\right)$ & 150.06 \\
& $\mathrm{R}^{2}$ & 0.9742 \\
& $\mathrm{q}_{\mathrm{m}}(\mathrm{mg} / \mathrm{g})$ & 45.37 \\
Elovich & $\left.\beta(\mathrm{mol} /)^{2}\right)$ & $3 \times 10^{-7}$ \\
& $\mathrm{E}(\mathrm{kJ} / \mathrm{mol})$ & 1.29 \\
Jovanovic & $\mathrm{R}^{2}(\mathrm{mg} / \mathrm{g})$ & 0.8452 \\
& $\mathrm{q}_{\mathrm{m}}(\mathrm{mg})$ & 38.31 \\
& $\mathrm{~K}_{\mathrm{e}}$ & 1.08 \\
& $\mathrm{R}^{2}$ & 0.9875 \\
& $\mathrm{q}_{\mathrm{m}}(\mathrm{mg} / \mathrm{g})$ & 17.03 \\
$\mathrm{~K}_{\mathrm{J}}$ & 0.11 \\
& $\mathrm{R}^{2}$ & 0.7859 \\
\hline
\end{tabular}

\section{Thermodynamic studies}

The thermodynamic parameters can shed more light on the energetic changes associated with the adsorption process. The values of the thermodynamic parameters like $\Delta \mathrm{G}^{\circ}, \Delta \mathrm{H}^{\circ}$ and $\Delta \mathrm{S}^{\circ}$ were predicted using the Gibbs plot (Figure 8). From Table 4, the negative value of the Gibbs free energy intimates that the $\mathrm{CV}$ removal process is spontaneous. The increase in the negative value at elevated temperatures indicates that the adsorbate uptake by the ACBS is enhanced at higher temperatures in the studied range. The positive value of the enthalpy change implies the endothermic nature of the CV adsorption by the adsorbent. The magnitude of enthalpic change may provide an insight about the kind of adsorption process involved. If the value of $\Delta \mathrm{H}^{\circ}$ is greater than 80 $\mathrm{kJ} / \mathrm{mol}$, the process is chemisorption which involves chemical bonding between the adsorbate and 
adsorbent surface. Conversely, when $\Delta H^{\circ}$ is lower than $80 \mathrm{~kJ} / \mathrm{mol}$, it signifies the adsorption process is physisorption (39). In this study, the value of $\Delta \mathrm{H}^{\circ}$ $(45.24 \mathrm{~kJ} / \mathrm{mol})$ indicates physisorption of adsorbate onto ACBS. The positive value of the entropy change implies the easiness of the adsorbate removal by the adsorbent and that the adsorption phenomenon is entropy-controlled rather than enthalpy-controlled (40). Similar outcome in thermodynamics has been reported for the adsorption of crystal violet using activated carbon prepared from waste active sludge (41).

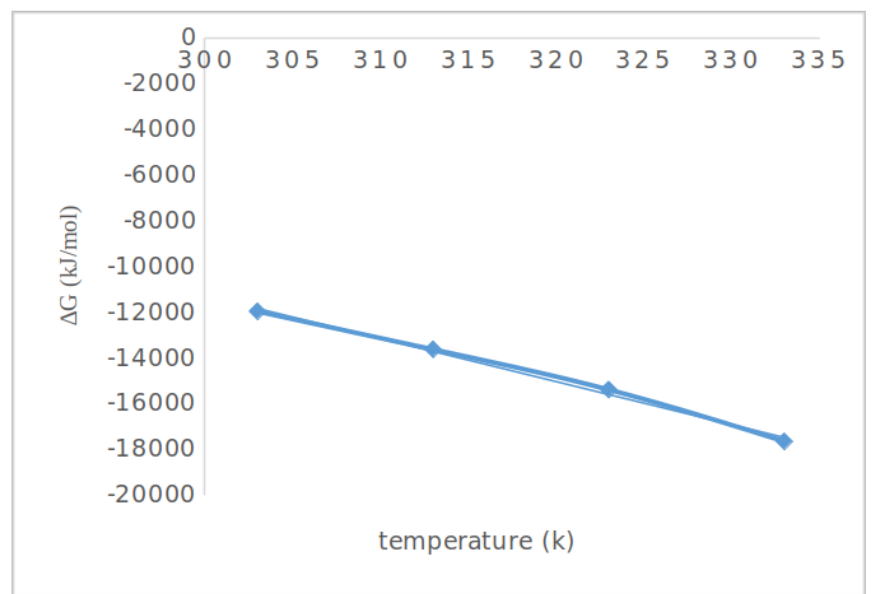

Figure 8: Gibbs plot for CV adsorption onto ACBS.

Table 4: Thermodynamic parameters of CV adsorption onto ACBS.

\begin{tabular}{llll}
\hline Temperature & $\Delta \mathrm{H}$ & $\Delta \mathrm{S}(\mathrm{kJ} / \mathrm{mol}$ & $\Delta \mathrm{G}$ \\
$(\mathrm{K})$ & $(\mathrm{kJ} / \mathrm{mol})$ & $\mathrm{K})$ & $(\mathrm{kJ} / \mathrm{mol})$ \\
\hline 303 & 45.24 & 0.19 & -11.96 \\
313 & & & -13.62 \\
323 & & & -14.38 \\
333 & & & -17.65 \\
\hline
\end{tabular}

\section{Regeneration studies}

The exhausted adsorbent is not safe for disposal due to the consequent secondary pollution. It is therefore imperative to propose a method for regeneration and reuse of adsorbent so as to lessen the burden on environment in terms of disposal of the sludge. Furthermore, recovered valuable adsorbates can be employed as precursors for the industrial synthesis of vital chemicals after appropriate separation (42). For this reason, different regeneration solutions were assessed for achieving significant replenishment of the spent adsorbent. Figure 9 demonstrates that maximum dye recovery (44.5\%) was achieved with $\mathrm{CH}_{3} \mathrm{COOH}$. This is ascribed to the fact that $\mathrm{CH}_{3} \mathrm{COOH}$ lowers the solution $\mathrm{pH}$ and the $\mathrm{H}^{+}{ }_{(\mathrm{aq})}$ compete favorably with the cationic dye ion $\mathrm{CV}^{+}$for the adsorption sites of the ACBS (43). It is worthy of mention that addition of other acidic agents $(\mathrm{HCl}$, $\mathrm{H}_{2} \mathrm{SO}_{4}$ and $\mathrm{HNO}_{3}$ ) did not yield relatively effective recovery as compared to $\mathrm{CH}_{3} \mathrm{COOH}$. This is ascribed to the reaction of these strong acids with $\mathrm{CV}$ leading to the formation of colorless compound (44). Similarly, in a basic solution, $\mathrm{OH}^{-}$ions attack the electrophilic carbon of the dye leading to its eventual discoloration (45). These findings were in concurrence with previous report on regeneration of CV-enriched adsorbent using different desorbing solutions (46).

The concentration of the best regeneration solution was also optimized in order to make the acetic acid regeneration solution technically viable for industrial application. The percent recovery was observed to increase with increasing concentration of $\mathrm{CH}_{3} \mathrm{COOH}$ and maximum recovery of $85.55 \%$ was accomplished using $0.5 \mathrm{M}$ solution (Figure 10). At high acid concentration, there was adequate $\mathrm{H}^{+}$in solution to compete with the $\mathrm{CV}^{+}$on the enriched-adsorbent (interference effect) and thus resulting in higher recovery. Similar phenomenon was highlighted for the desorption of malachite green using varying concentration of $\mathrm{CH}_{3} \mathrm{COOH}$ (47).

The influence of contact time on CV desorption from the CV-enriched ACBS is illustrated in Figure 11. It may be observed that the dye desorbed very quickly in the first $20 \mathrm{~min}$ and then attained maximum elution of $85.29 \%$ in $30 \mathrm{~min}$. The percent recovery remained nearly steady after this phase, signaling equilibrium of the process. Previous work on CV desorption from grapefruit peel also highlighted similar trend (48).

The reusability of the adsorbent is typically considered as a crucial character for making adsorption more operationally and economically advantageous (49). Figure 12 illustrates the results of the adsorptiondesorption of CV for five successive cycles. It is seen that the adsorption efficiency for CV dropped from $97.87 \%$ in the first cycle to $92.08 \%$ in the fifth cycle. This gave a hint that the adsorbent can be consecutively utilized without appreciable decline in adsorption efficacy of CV. Similar phenomenon was reported for the recycling of activated carbon after five successive adsorption-desorption cycles (50). 


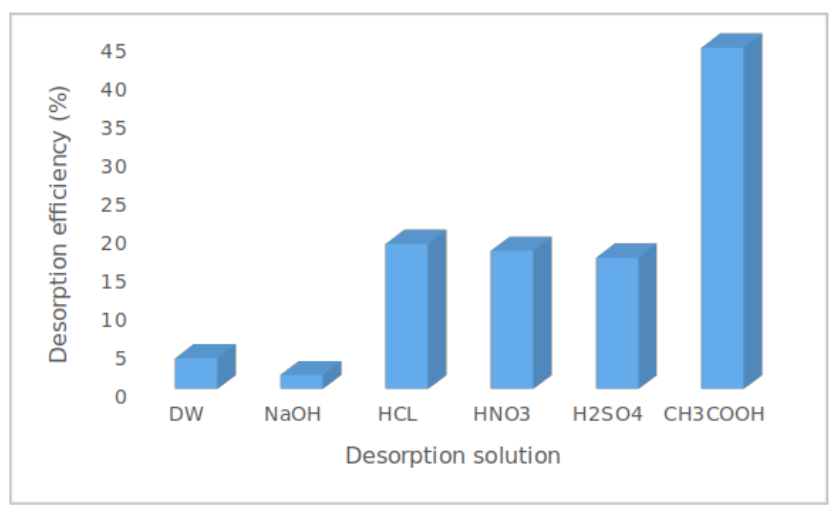

Figure 9: Screening of desorbing solutions for CV recovery.

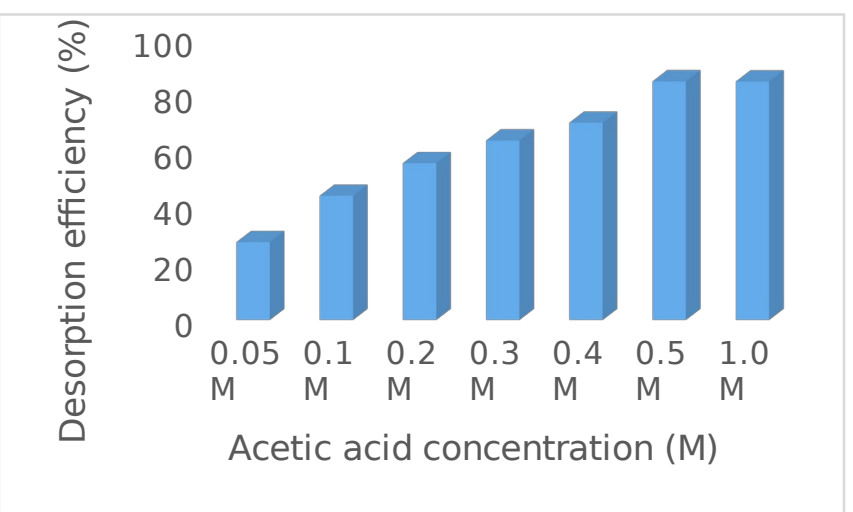

Figure 10: Influence of desorbing solution concentration on CV desorption from ACBS.

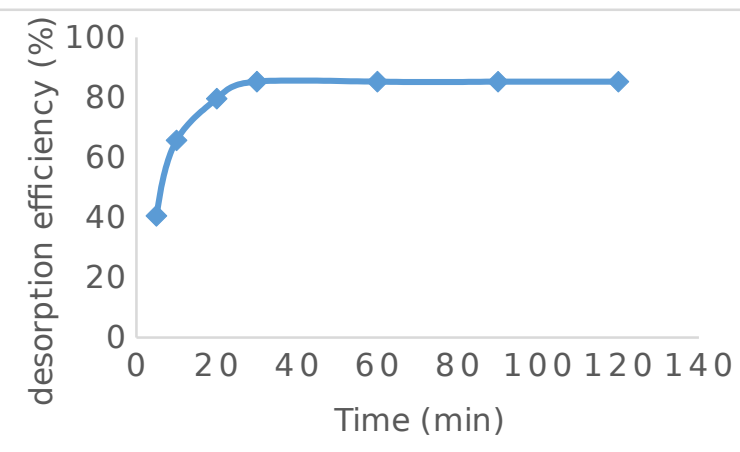

Figure 11: Influence of contact time on CV desorption from ACBS.

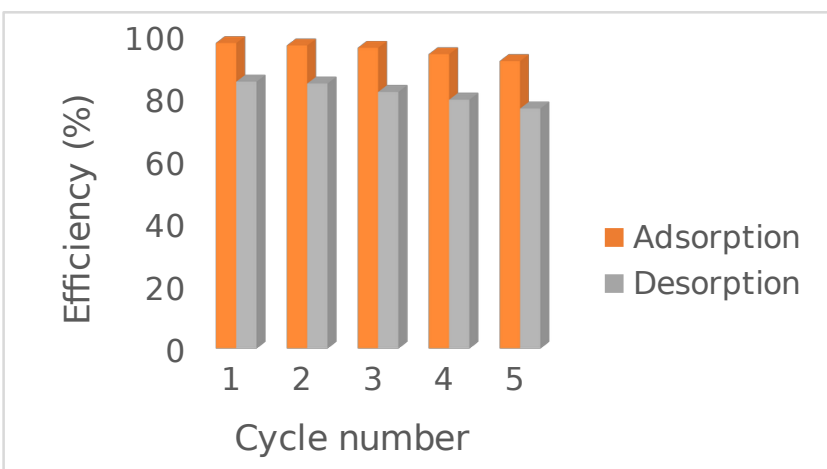

Figure 12: Reusability of ACBS for successive adsorption-desorption cycles of CV.

\section{CONCLUSION}

The activated carbon was prepared from Balanites aegyptiaca seed shell via a two-step chemical activation technique with sodium hydroxide. SEM analysis clearly reveals the variation in the morphology of the precursor and the prepared activated carbon. The EDS spectrum of the ACBS showed peaks for $\mathrm{C}, \mathrm{O}, \mathrm{N}, \mathrm{P}, \mathrm{S}$, and $\mathrm{Cl}$. Kinetics match well to pseudo-second-order model $\left(R^{2}>0.999\right)$. The diffusion studies indicates the involvement of both external diffusion and internal diffusion in the CV adsorption process. The isothermal Freundlich model was the best to represent the equilibrium data $\left(R^{2}=\right.$ $0.9916 ; 1 / \mathrm{n}=0.56)$, signifying the multilayer coverage of $\mathrm{CV}$ on the heterogeneous surface of the ACBS. The sequence of the best fitting isotherm model was found to be: Freundlich $>$ Elovich $>$ Langmuir $>$ Temkin $>\mathrm{D}-\mathrm{R}>$ Jovanovic. The data from thermodynamic study intimates the practicability $(\Delta G$ $=-17.65 \mathrm{~kJ} / \mathrm{mol})$, easiness $(\Delta \mathrm{S}=0.19 \mathrm{~kJ} / \mathrm{mol} \mathrm{K})$ and endothermicity $\left(\Delta \mathrm{H}^{\circ}=45.24 \mathrm{~kJ} / \mathrm{mol}\right)$ of the process. Regeneration studies reveals the effectiveness of $\mathrm{CH}_{3} \mathrm{COOH}$ solution in $\mathrm{CV}$ recovery (85.55\%). The findings affirmed the suitability of ACBS for crystal violet removal from aqueous medium.

\section{REFERENCES}

1. Abbas M, Harrache Z, Trari M. Removal of gentian violet in aqueous solution by activated carbon equilibrium, kinetics, and thermodynamic study. Adsorption Science \& Technology. 2019;37(7-8):56689.

2. Biçer G, Gönen F. Telon blue AGLF adsorption by NiO-based nanomaterials: equilibrium, kinetic, and thermodynamic approach. Journal of the Turkish Chemical Society Section A: Chemistry. 2017;4(3):675-90. 
3. Yildiz A. Adsorption of acid red 114 onto Fe304@Caffeic acid recyclable magnetic nanocomposite. Journal of the Turkish Chemical Society Section A: Chemistry. 2017;4(1):327-40.

4. Jadhav JP, Kalyani DC, Telke AA, Phugare SS, Govindwar SP. Evaluation of the efficacy of a bacterial consortium for the removal of color, reduction of heavy metals, and toxicity from textile dye effluent. Bioresource Technology. 2010;101:165-73.

5. Jarup L. Hazards of heavy metal contamination. British Medical Bulletin. 2003;68:167-82.

6. Mashkoor F, Nasar A, Inamuddin, Asiri AM. Exploring the reusability of synthetically contaminated wastewater containing crystal violet dye using Tectona grandis sawdust as a very low-cost adsorbent. Scientific Reports. 2018;8:8314.

7. Robinson T, McMullan G, Marchant R, Nigam P. Remediation of dyes in textile effluent: A critical review on current treatment technologies with a proposed alternative. Bioresource Technology. 2001;77:247-55.

8. Dandil S, Sahbaz DA, Acikgoz C. High performance adsorption of hazardous triphenylmethane dye-crystal violet onto calcinated waste mussel shells. Water Quality Research Journal. 2019;54(3): 249-56.

9. Chackraborty S, Chowdhury S, Saha, PD. Adsorption of crystal violet from aqueous solution onto $\mathrm{NaOH}$ modified rice husk. Carbohydrate Polymers. 2011;86:1533-41.

10. Mittal A, Mittal J, Kaur D, Gupta VK. Adsorption of hazardous crystal violet from wastewater by waste materials. Journal of Colloid and Interface Science. 2010; 343: 463-73.

11. Aljeboree A. Adsorption of crystal violet by Fugas sawdust from aqueous solution. International Journal of ChemTech Research. 2016; 9(3):412-23.

12. Nazifa, TA, Habba N, Aris A, Hadibarata T. Adsorption of procion red MX-5B and crystal violet dyes from aqueous solution onto corncob activated carbon. Journal of the Chinese Chemical Society. 2017;65(2):259-70.

13. Pehlivan E. Production and characterization of activated carbon from pomegranate pulp by phosphoric acid. JOTSCA. 2018;(5 sp. is. 1):1-8.

14. Hall JB, Walker DH. Balanites aegyptiaca-A monograph. School of Agricultural and Forest Sciences, University of Wales, Banger, UK. 1991;1-65.
15. Wang X, Wang S, Yin X, Chen J, Zhu L. Activated carbon preparation from cassava residue using a twostep $\mathrm{KOH}$ activation: preparation, micropore structure and adsorption capacity. Journal of Biobased Materials and Bioenergy. 2014;8(20):1-8.

16. Langergren $\mathrm{S}$. About the theory of so-called adsorption of soluble substances. Band. 1898; 24(4): 1-39.

17. Ho YS, McKay G. Pseudo-second-order model for sorption processes. Process Biochemistry. 1999;34: 451-65.

18. Hameed BH, Din ATM, Ahmad AL. Adsorption of methylene blue onto bamboo-based activated carbon: kinetics and equilibrium studies. Journal of Hazardous Materials. 2007;141:819-25.

19. Weber WJ, Morris JCJ. Kinetics of adsorption on carbon from solutions. Sanitary Engineering Division ASCE. 1963;89: 31-60.

20. Boyd GE, Adamson AW, Myers JLS. The exchange of ions from aqueous solution by organic zeolites, II: Kinetic. Journal of the American Chemical Society. 1947;69:2836-48.

21. Ayawei N, Ebelegi AN, Wankasi D. Modelling and interpretation of adsorption isotherms. Journal of Chemistry. 2017;3039817.

22. Wu J, Xia A, Chen C, Feng L, Su X, Wang X. Adsorption thermodynamics and dynamics of three typical dyes onto bio-adsorbent spent substrate of Pleurotus eryngii. International Journal of Environmental Research and Public Health. 2019;16(679):1-11.

23. Ahmad MA, Ahmad N, Bello OS. Adsorptive removal of malachite green dye using durian seedbased activated carbon. Water Air Soil Pollution. 2014;225:1-18.

24. Saheed IO, Adekola FA, Olatunji GA. Sorption study of methylene blue on activated carbon prepared from Jatropha curcas and Terminalia catappa seed coats. JOTSCA. 2017;4(1):375-94.

25. Nethaji S, Sivasamy A. Removal of hexavalent chromium from aqueous solution using activated carbon prepared from walnut shell biomass through alkali impregnation processes. Clean Technologies and Environmental Policy. 2014;16:361-8.

26. Ahmad MA, Afandi NS, Adegoke KA, Bello OS. Optimization and batch studies on adsorption of malachite green dye using rambutan seed activated 
carbon. Desalination and Water Treatment. 2015;57(45):21487-511.

27. Gorzin F, Abadi MMBR. Adsorption of $\mathrm{Cr}(\mathrm{VI})$ from aqueous solution by adsorbent prepared from paper mill sludge: kinetics and thermodynamic studies. Adsorption Science \& Technology. 2017;36(1-2):14969.

28. Al-Othman ZA, Ali R, Naushad M. Hexavalent chromium removal from aqueous medium by activated carbon prepared from peanut shell: adsorption kinetics, equilibrium and thermodynamic studies. Chemical Engineering Journal. 2012;184:23847.

29. Ma J, Yu Fei, Zhou L, Jin L, Yang M, Luan J, Tang $Y$, Fan $\mathrm{H}$, Yuan Z, Chen J. Enhanced adsorptive removal of methyl orange and methylene blue from aqueous solution by alkali-activated multiwalled carbon nanotubes. Applied Materials and Interfaces. 2012;4:5749-60.

30. Pakade VE, Nchoe OB, Hlungwane L, Tavengwa NT. Sequestration of hexavalent chromium from aqueous solution by activated carbon derived from macadamia nutshells. Water Science and Technology. 2017;75(1):196-206.

31. Ahsaine HA, Anfar Z, Zbair M, Ezahri M, El Alem N. Adsorptive removal of methylene blue and crystal violet onto micro-mesoporous $\mathrm{Zr3O} /$ activated carbon composite: a joint experimental and statistical modeling considerations. Journal of Chemistry. 2018: 1-14.

32. Al-Azabi K, Al-Marog S, Abukrain A, Sulyman M. Equilibrium isotherm studies of dye adsorption onto orange peel powder. Chemistry Research Journal. 2018;3(1):45-59.

33. Akalin HA, Hicsonmez U, Yilmaz H. Removal of Cesium from aqueous solution by adsorption onto Sivas-Yildizeli (Türkiye) vermiculite: equilibrium, kinetic and thermodynamic studies. Journal of the Turkish Chemical Society Section A: Chemistry. 2018;5(1):85-116.

34. Kumar M, Tamilarasan R. Modeling studies for the removal of methylene blue from aqueous solution using Acacia fumosa seed shell activated carbon. Journal of Environmental Chemical Engineering. 2013;1:1108-16.

35. Experimental and DFT studies of the removal of pharmaceutical metronidazole from water using polypyrrole. International Journal of Industrial Chemistry. 2019;10:269-79.
36. Gubernak M, Zapala W, Kaczmarski K. Analysis of benzene adsorption equilibria on an RP-18e chromatographic column. Acta Chromatographica. 2003;13:38-59.

37. Kyziol-Komosinska J, Rosik-Dulewska C, Franus M, Antoszczyszyn-Szpicka P, Czupiol J, Krzyzewska I. Sorption Capacities of Natural and Synthetic Zeolites for $\mathrm{Cu}(\mathrm{II})$ Ions. Polish Journal of Environmental Studies. 2015;24:1111-23.

38. Foo KY, Hameed $\mathrm{BH}$. Insights into the modeling of adsorption isotherm systems. Chemical Engineering Journal. 2010;156: 2-10.

39. Akar E, Altinisik A, Seki Y. Using of activated carbon produced from spent tea leaves for the removal of malachite green from aqueous solution. Ecological Engineering. 2013;52:19- 27.

40. Asadullah, Kaewsichan L, Tohdee K. Adsorption of hexavalent chromium onto alkali-modified biochar derived from Lepironia articulata: A kinetic, equilibrium, and thermodynamic study. Water Environment Research. 2019;1-14.

41. Sahbaz DA, Dandil S, Acikgoz C. Removal of crystal violet dye by a novel adsorbent derived from waste active sludge used in wastewater treatment. Water Quality Research Journal. 2019; 54(4):299-308.

42. Sharma K, Vyas RK, Dalai AK. Thermodynamic and kinetic studies of methylene blue degradation using reactive adsorption and its comparison with adsorption. Journal of Chemical and Engineering Data. 2017;62(11):3651-62.

43. Ogata F, Nakamura T, Kawasaki N. Adsorption capability of virgin and calcined wheat bran for molybdenum present in aqueous solution and elucidating the adsorption mechanism by adsorption isotherms, kinetics and regeneration. Journal of Environmental Chemical Engineering. 2018;6(4):445966.

44. Nidheesh PV, Gandhimathi R, Ramesh ST, Singh TSA. Adsorption and desorption characteristics of crystal violet in bottom ash column. Journal of Urban and Environmental Engineering. 2011;6(1):18-29.

45. Hassan MAE, Fayoumi LMA, El Jamal MM. Kinetic study of the discoloration of triphenylmethane dyes in function of $\mathrm{pH}$, salt effect. Journal of the University of Chemical Technology and Metallurgy. 2011;46(4):395400.

46. Neupane S, Ramesh ST, Gandhimathi R, Nidheesh PV. Pineapple leaf powder as a biosorbent for the removal of crystal violet from aqueous solution. 
Desalination and water treatment. 2014;54(7):204154.

47. Yunusa U, Ibrahim MB. Reclamation of malachite green-bearing wastewater using desert date seed shell: adsorption isotherms, desorption and reusability studies. Chemsearch Journal. 2019;10(2):112-22.

48. Saeed A, Sharif M, Iqbal M. Application potential of grapefruit peel as dye sorbent: kinetics, equilibrium and mechanism of crystal violet adsorption. Journal of Hazardous Materials. 2010; 179:564-72.
49. Ali I, Peng C, Ye, T, Naz I. Sorption of cationic malachite green dye on phytogenic magnetic nanoparticles functionalized by 3-marcaptopropanic acid. Royal Society of Chemistry Advances. 2018;8:8878-97.

50. Azaman SAH, Afandi A, Hameed BH, Mohd Din AT. Removal of malachite green from aqueous phase using coconut shell activated carbon: adsorption, desorption, and reusability studies. Journal of Applied Science and Engineering. 2018;21(3):317-30. 